\title{
Solvent Extraction of Tellurium from Chloride Solutions Using Tri-n-butyl Phosphate: Conditions and Thermodynamic Data
}

\author{
Dongchan Li, ${ }^{1,2}$ Yafei Guo, ${ }^{1}$ Tianlong Deng, ${ }^{1,3}$ Yu-Wei Chen, ${ }^{1,3}$ and Nelson Belzile ${ }^{1,3}$ \\ ${ }^{1}$ Tianjin Key Laboratory of Marine Resources and Chemistry, Tianjin University of Science and Technology, \\ Tianjin 300457, China \\ ${ }^{2}$ Engineering Research Center of Seawater Utilization Technology, Ministry of Education, Hebei University of Technology, \\ Tianjin 300130, China \\ ${ }^{3}$ Department of Chemistry \& Biochemistry, Laurentian University, Sudbury, ON, Canada P3E 2C6
}

Correspondence should be addressed to Tianlong Deng; tldeng@tust.edu.cn and Nelson Belzile; nbelzile@laurentian.ca

Received 10 January 2014; Accepted 17 February 2014; Published 16 March 2014

Academic Editors: L. Y. Chen and K. Lázár

Copyright (C) 2014 Dongchan Li et al. This is an open access article distributed under the Creative Commons Attribution License, which permits unrestricted use, distribution, and reproduction in any medium, provided the original work is properly cited.

\begin{abstract}
The extractive separation of tellurium (IV) from hydrochloric acid media with tri-n-butyl phosphate (TBP) in kerosene was investigated. The dependence on the extraction of tellurium species, concentrations of tellurium and TBP, extraction time and stage, organic/aqueous ratio, and interferences from coexist metallic ions were examined and are discussed. Besides, the stripping agent and stripping time were also studied. It was found that the extraction reaction corresponds to the neutral complex formation mechanism and the extracted species is $\mathrm{TeCl}_{4} \cdot 3 \mathrm{TBP}$ and that the extraction process is exothermic. The thermodynamic parameters of enthalpy $(\Delta H)$, entropy $(\Delta S)$, and free energy $(\Delta G)$ of the extraction process were evaluated at $-26.2 \mathrm{~kJ} \cdot \mathrm{mol}^{-1},-65.6 \mathrm{~J} \cdot \mathrm{mol}^{-1} \cdot \mathrm{K}^{-1}$, and $-7.0 \mathrm{~kJ} \cdot \mathrm{mol}^{-1}$, respectively at $293 \mathrm{~K}$.
\end{abstract}

\section{Introduction}

Tellurium (Te) is widely used in various fields of human activity. As an excellent semiconductor of scattered elements, Te has unique applications in the electronic industry especially in the area of thermoelectricity, either for power generation as lead telluride or for refrigeration as bismuth telluride [1]. The other main application of Te is in metallurgy as an alloy with cast iron, copper, and stainless steel and when it is added to lead, it increases its strength and prevents corrosion [2]. It is also used in the rubber, glass, and ceramic industries. Meanwhile, Te is present in small amounts in the earth's crust with the average abundance of $\sim 1 \mu \mathrm{g} \cdot \mathrm{kg}^{-1}(\mathrm{ppb})$. The proven and recoverable reserves of metallic Te are only $\sim 38000$ tons in the world.

Due to this situation, extraction and separation of $\mathrm{Te}$ from complex samples are of great importance for the development of existing resources. Various solvent extraction methods have been used for the recovery of Te. The use of extractants tris-(2-ethyl hexyl) phosphate [3], tributyl phosphate (TBP) [4-6], 2,3,5-triphenyltetrazolium chloride [7], triphenylarsine oxide and tributyl-phosphine oxide [8], tri-isooctylamine [2], and $N$-n-octylaniline $[1,9]$ has been reported for the separation and extraction of Te. Extractant TBP [4-6] has been widely used for Te extraction due to its high efficiency, low consumption, and the simplicity of operation. The mechanism of Te separation from selenium in hydrochloric acid media with TBP in kerosene has been investigated in a batch-stirred glass cell. The extracted species and the extraction enthalpy were determined [4]. The mass transfer of Te(IV) between an aqueous and an organic phase has been studied in a modified Lewis cell with the organic phase being composed of TBP in kerosene at varying volume ratios [5]. A mass transfer model has been developed to indicate reaction front position and the extent of extraction of $\mathrm{Te}(\mathrm{IV})$ under different experimental conditions [6]. This study explored systematically the parameters affecting the extraction and stripping of Te, the extraction mechanism and allowed to estimate the thermodynamics factors of the overall extraction process. 


\section{Experiment}

2.1. Reagents and Materials. All chemicals and solvents used in this study were of analytical reagent grade and the water was double distilled (DDW). The tri-butyl-phosphate (TBP) was supplied by Chengdu Kelong Corporation, China. It was diluted with aviation kerosene. The Te(IV) solution was prepared by dissolving the appropriate mass of potassium tellurite $\left(\mathrm{K}_{2} \mathrm{TeO}_{3}\right)$ (Beijing Zhongliante Corporation, China) in $10 \%(\mathrm{v} / \mathrm{v})$ hydrochloric acid and diluted to volume with DDW. The Te(VI) solution was prepared from sodium tellurate $\left(\mathrm{Na}_{2} \mathrm{TeO}_{4} \cdot 2 \mathrm{H}_{2} \mathrm{O}\right.$ ) (Alfa Aesar, USA) in $10 \%(\mathrm{v} / \mathrm{v}$ ) hydrochloric acid.

2.2. General Procedure. Aqueous solutions of $\mathrm{Te}(\mathrm{IV})$ were made with different concentrations of $\mathrm{HCl}$ to reach the required acidity. Organic solutions were prepared by diluting measured volumes of TBP with aviation kerosene. Then, these two solutions were transferred to a $125 \mathrm{~mL}$ separatory funnel according to selected phase ratios and the mixture was shaken for $3 \mathrm{~min}$ at $200 \mathrm{rpm}$ as controlled by the HZQ-C rocking incubator (Harbin Donglian Electronic \& Technology Development Co. Ltd., China). The two layers were allowed to settle and separate. The aqueous layer was discarded less than 1 minute. Tellurium(IV) from the aqueous phase was determined with hydride generation atomic florescence spectrometry (HG-AFS, model 2202, Beijing Haiguang Instrument Co. Ltd., China) with an uncertainty within $0.5 \%$ in mass [10]. Te concentrations in the organic phase were calculated from the different concentration values in the aqueous phase before and after the extraction. Then $\mathrm{Te}(\mathrm{IV})$ was stripped from the organic phase with $20 \%(\mathrm{w} / \mathrm{v})$ ammonium chloride. The presence of coexisting metallic ions to the Te extraction process was measured by a Perkin-Elmer Optima 5300V ICP-OES with an uncertainty within $0.5 \%$ in mass.

\section{Results and Discussion}

3.1. Choice of Diluents. The diluent plays a very important role in the solvent extraction process. It can change some physicochemical properties of the organic phase, such as density, viscosity, solubility parameter, and dipole moment, which affect the extraction efficiency. Moreover, the diluent itself cannot extract the metal to a significant quantity. On this basis, Chowdhury and Sanyal investigated the influence of diluents on the extraction of $\mathrm{TeCl}_{4}$ from the aqueous hydrochloric acid solution with TBP [11]. They divided the common diluents into two broad categories: polar and nonpolar. The result suggests that kerosene and hexane are the best and most competitive diluents for the system. In this study, we choose kerosene because of its low cost and minimum toxicity. It was also observed that the separation after the extraction process was quick and led to a clear phase.

3.2. Effect of Acid and Acid Concentration for Te(IV). The extraction was carried out with an aqueous solution of $0.5 \mathrm{~g} / \mathrm{L}$ $\mathrm{Te}(\mathrm{IV})$ and an organic solution containing 30\% (v/v) TBP in

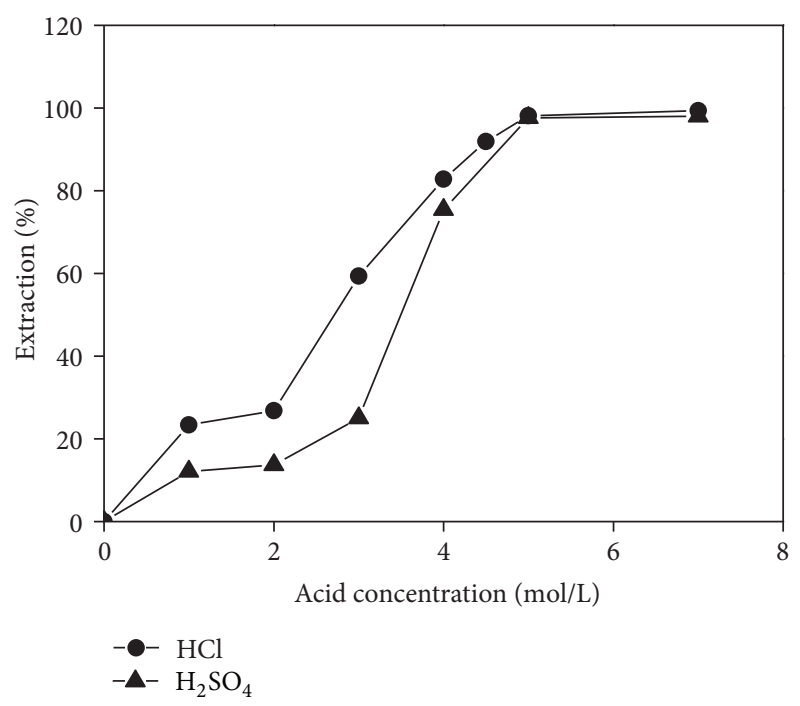

FIGURE 1: Effect of different concentrations of $\mathrm{HCl}$ and $\mathrm{H}_{2} \mathrm{SO}_{4}$ on $\mathrm{Te}(\mathrm{IV})$ extraction.

TABLE 1: Effect of $\mathrm{HCl}$ concentration on $\mathrm{Te}(\mathrm{VI})$ extraction.

\begin{tabular}{lc}
\hline $\mathrm{HCl} /\left(\mathrm{mol} \cdot \mathrm{L}^{-1}\right)$ & Extraction $/ \%$ \\
\hline 1 & 0.61 \\
3 & 0.62 \\
5 & 2.98 \\
\hline
\end{tabular}

kerosene at an organic/aqueous $(\mathrm{O} / \mathrm{A})$ volume ratio of 1 . The effects of two acids sulfuric acid $\left(\mathrm{H}_{2} \mathrm{SO}_{4}\right)$ and hydrochloric acid $(\mathrm{HCl})$ on $\mathrm{Te}(\mathrm{IV})$ extraction were investigated. The results presented in Figure 1 indicate that the extraction of Te(IV) increased with the increasing concentration of both acids and that $\mathrm{Te}(\mathrm{IV})$ was almost completely extracted in $7 \mathrm{~mol} / \mathrm{L} \mathrm{HCl}$ and $\mathrm{H}_{2} \mathrm{SO}_{4}$. It was also found that the extraction efficiency started to be higher when the concentration of both acid was over $4 \mathrm{~mol} / \mathrm{L}$. However, in view of the serious corrosion effect of $\mathrm{H}_{2} \mathrm{SO}_{4}$, a $4.5 \mathrm{~mol} / \mathrm{L} \mathrm{HCl}$ was chosen for $\mathrm{Te}(\mathrm{IV})$ extraction in all additional experiments.

3.3. Extraction of Tellurium(VI). The extraction was carried out with an aqueous solution of $0.5 \mathrm{~g} / \mathrm{L} \mathrm{Te}(\mathrm{VI})$ and an organic solution containing 30\% (v/v) TBP in kerosene at an O/A ratio of 1 using $4.5 \mathrm{~mol} / \mathrm{L} \mathrm{HCl}$. The mixture solution was shaken for $3 \mathrm{~min}$ at $200 \mathrm{rpm}$. The results (Table 1) show that $\mathrm{Te}(\mathrm{VI})$ was hardly extracted in the $\mathrm{HCl}$ medium with the low extraction efficiency. This suggests that $\mathrm{Te}(\mathrm{VI})$ does not interfere in the extraction of Te(IV) in $4.5 \mathrm{~mol} / \mathrm{L} \mathrm{HCl}$, as it was carried out in this study.

3.4. Effect of Contact Time. The solution mixture of the two phases was shaken during periods varying from 1 to $20 \mathrm{~min}$. The results show that the extraction was over $90.0 \%$ for $1 \mathrm{~min}$ and that the maximum extraction of $91.9 \%$ was obtained after 3 min of contact time. However, after $3 \mathrm{~min}$, the extraction slightly decreased with increasing contact time (Figure 2). The extraction efficiency declined to $88.3 \%$ when the contact 
TABLE 2: Effect of TBP concentration on Te(IV) extraction.

\begin{tabular}{lccccc}
\hline TBP/\% (v/v) & $C_{\mathrm{TBP}} /\left(\mathrm{mol} \cdot \mathrm{L}^{-1}\right)$ & $\log C_{\mathrm{TBP}}$ & Extraction/\% & $D$ & \\
\hline 10 & 0.37 & -0.43 & 14.03 & 0.16 & -0.79 \\
20 & 0.74 & -0.13 & 67.54 & 0.32 \\
30 & 1.11 & 0.04 & 91.88 & 1.08 & 1.32 \\
40 & 1.47 & 0.17 & 92.37 & 12.11 & 1.05 \\
50 & 1.84 & 0.27 & 94.25 & 16.39 \\
\hline
\end{tabular}

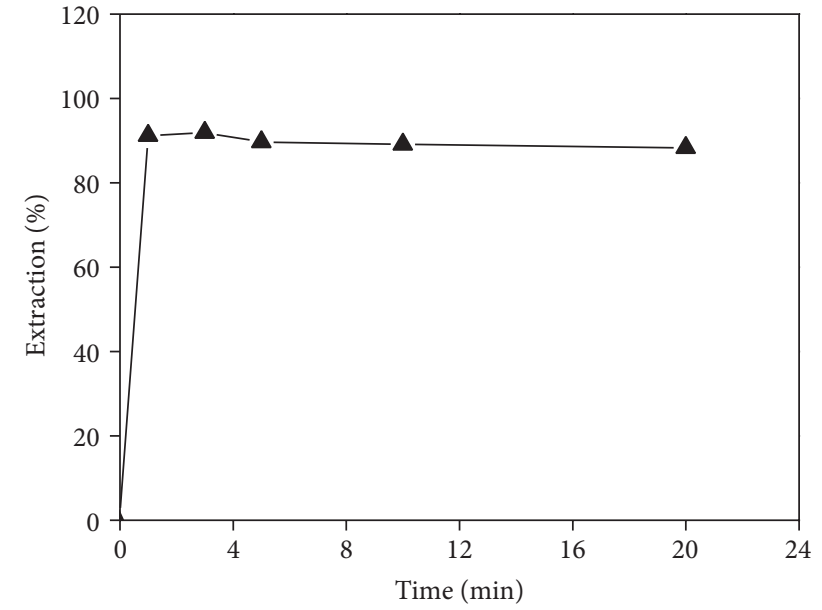

FIGURE 2: Effect of contact time on Te(IV) extraction.

time was extended to $20 \mathrm{~min}$. This may simply be due to the competitive extraction of aqueous phase and new extraction equilibrium established with the extension of time. A 3 min contact time is therefore recommended to reach the high extraction efficiency and ensure the optimum time of the metal ion extracted from the hydrochloric acid medium.

3.5. Effect of TBP Concentration in the Organic Phase. The effect of the concentration of extractant TBP in the organic phase was also examined. Data presented in Table 2 show an obvious increase in Te extraction as the extractant concentration increased. It was found that the extraction efficiency was much lower than $90 \%$ when the TBP concentration in kerosene was under $30 \%(\mathrm{v} / \mathrm{v})$. In consideration of cost and consumption, a $30 \%(\mathrm{v} / \mathrm{v})$ TBP concentration in kerosene was selected as the optimum condition even though the higher TBP concentrations of $40 \%$ and $50 \%$ showed a little higher extraction efficiency.

The experiment also demonstrated that three TBP ligands react with one Te as revealed by the plot of $\log D$ versus $\log$ TBP. It generates a linear relationship with a slope very close to 3 at 2.96 (Figure 3).

Here are the corresponding equations [4]:

$$
\mathrm{TeCl}_{4(\text { aq })}+m \mathrm{TBP}_{(\text {org })}=\mathrm{TeCl}_{4} \cdot m \mathrm{TBP}_{(\text {org })},
$$

extraction equilibrium $\left(K_{\mathrm{ex}}\right)$ :

$$
K_{\mathrm{ex}}=\frac{\left[\mathrm{TeCl}_{4} \cdot m \mathrm{TBP}\right]_{\mathrm{org}}}{\left[\mathrm{TeCl}_{4}\right]_{\mathrm{aq}}[\mathrm{TBP}]_{\mathrm{org}}^{m}},
$$

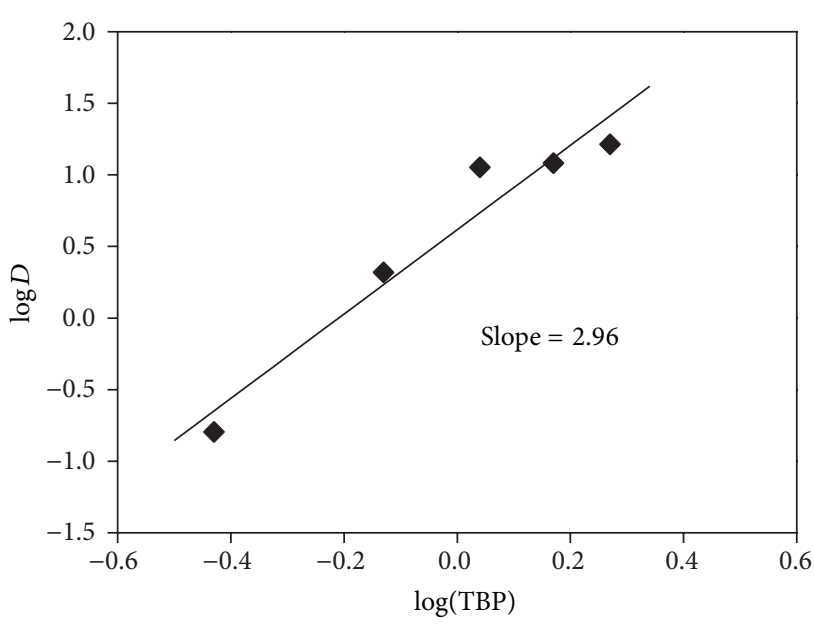

FIgURE 3: $\log D$ as a function of $\log$ TMP concentration.

distribution coefficient $(D)$ :

$$
D=\frac{\left[\mathrm{TeCl}_{4} \cdot m \mathrm{TBP}\right]_{\mathrm{org}}}{\left[\mathrm{TeCl}_{4}\right]_{\mathrm{aq}}} .
$$

Therefore,

$$
K_{\mathrm{ex}}=\frac{D}{[\mathrm{TBP}]_{\mathrm{org}}^{m}} .
$$

For a constant $\left[\mathrm{Cl}^{-}\right]$

$$
\log D=m \log [\mathrm{TBP}]_{\text {org }}+\text { constant. }
$$

Figure 3 confirms that the value of the slope $m$ is 2.96 . The extraction reaction is therefore as follows:

$$
\mathrm{TeCl}_{4(\mathrm{aq})}+3 \mathrm{TBP}_{(\text {org })}=\mathrm{TeCl}_{4} \cdot 3 \mathrm{TBP}_{(\text {org })} .
$$

3.6. Effect of Temperature. The effect of temperature on $\mathrm{Te}$ extraction from an aqueous phase of $0.5 \mathrm{~g} / \mathrm{L}$ in $4.5 \mathrm{~mol} / \mathrm{L} \mathrm{HCl}$ with a $30 \%(\mathrm{v} / \mathrm{v})$ TBP solution in kerosene was studied at 5 different temperatures. The results of Table 3 show that the extraction decreased with the increasing temperature.

The Van't Hoff equation shows the change on the distribution coefficient $(D)$ with temperature and allows calculating the enthalpy of the Te extraction as

$$
\frac{-\Delta H}{2.303 R}=\frac{D(\log D)}{D(1 / T)} .
$$


TABLE 3: Effect of temperature on Te(IV) extraction.

\begin{tabular}{lcccc}
\hline$T /(\mathrm{K})$ & $1 / T \times 10^{-4} /\left(\mathrm{K}^{-1}\right)$ & Extraction $/ \%$ & $D$ & $\log D$ \\
\hline 283 & 35.34 & 96.51 & 27.65 & 1.44 \\
293 & 34.13 & 94.64 & 17.66 & 1.25 \\
303 & 33.00 & 91.88 & 11.32 & 1.05 \\
313 & 31.95 & 89.22 & 8.28 & 0.92 \\
323 & 30.96 & 87.82 & 7.21 & 0.86 \\
\hline
\end{tabular}

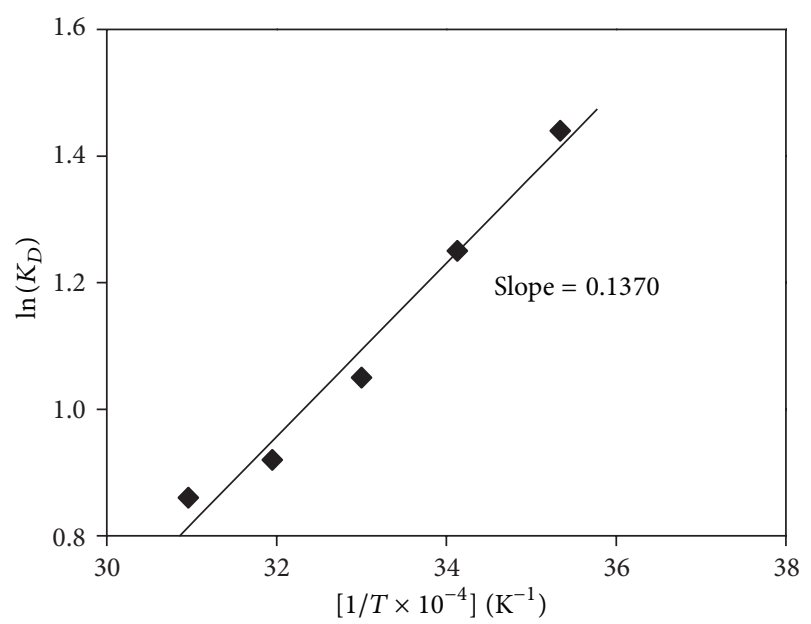

FIgURE 4: Effect of temperature on Te(IV) extraction.

TABLE 4: Values of $\Delta G$ and $\Delta S$ of the extraction process at different temperatures.

\begin{tabular}{lccc}
\hline$T /(\mathrm{K})$ & $\log D$ & $\Delta G /\left(\mathrm{kJ} \cdot \mathrm{mol}^{-1}\right)$ & $\Delta S /\left(\mathrm{J} \cdot \mathrm{mol}^{-1} \cdot \mathrm{K}^{-1}\right)$ \\
\hline 283 & 1.44 & -7.80 & -65.12 \\
293 & 1.25 & -7.01 & -65.60 \\
303 & 1.05 & -6.09 & -66.47 \\
313 & 0.92 & -5.51 & -66.20 \\
323 & 0.86 & -5.31 & -64.77 \\
\hline
\end{tabular}

The plot of $\log D$ versus $1 / T \times 10^{-4}$ (Figure 4 ) generates a linear relationship with a slope of 0.1370 . The enthalpy change $(\Delta H)$ of the reaction was estimated at $-26.23 \mathrm{~kJ} \cdot \mathrm{mol}^{-1}$, which indicates an exothermic reaction. This agrees well with a value of $-26.8 \mathrm{~kJ} \cdot \mathrm{mol}^{-1}$ reported [4] for the same process under similar conditions.

The changes in free energy $(\Delta G)$ and entropy $(\Delta S)$ were then calculated using the following equations:

$$
\begin{gathered}
\Delta G=-2.303 R T \log D, \\
\Delta S=\frac{\Delta H-\Delta G}{T} .
\end{gathered}
$$

The negative values of the free energy $\Delta G$ suggest that the reaction is favorable in nature. The negative enthalpy $\Delta S$ values indicate that the extraction is more favorable at low temperature (Table 4 ). Therefore, the ambient temperature range $(283-303 \mathrm{~K})$ can be considered as optimum for $\mathrm{Te}$

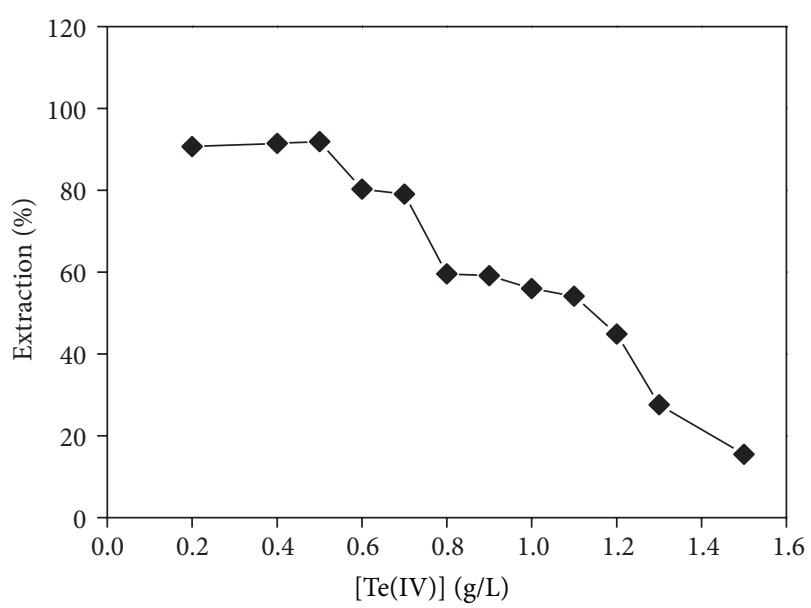

FIGURE 5: Effect of the initial concentrations of Te(IV) on extraction.

TABLE 5: Effect of the volume phase ratio on Te(IV) extraction.

\begin{tabular}{lc}
\hline $\mathrm{O} / \mathrm{A} /\left(V_{o} / V_{w}\right)$ & Extraction of $\mathrm{Te} / \%$ \\
\hline $1: 2$ & 77.79 \\
$1: 1$ & 91.88 \\
$2: 1$ & 96.27 \\
\hline
\end{tabular}

TABLE 6: Effect of repeated extraction on Te(IV) extraction.

\begin{tabular}{lc}
\hline Stage & Extraction of Te (additive) $/ \%$ \\
\hline 1 & 91.88 \\
2 & 97.76 \\
3 & 98.97 \\
\hline
\end{tabular}

extraction. There are no values of $\Delta G$ or $\Delta S$ reported in the literature for that extraction process.

3.7. Loading Capacity of TBP in the Extraction. Aqueous solutions with various concentrations of Te were extracted at a fixed concentration of $30 \%(\mathrm{v} / \mathrm{v})$ TBP in kerosene and $4.5 \mathrm{~mol} / \mathrm{L} \mathrm{HCl}$. The extraction efficiency decreased sharply from $91.88 \%$ to $15.51 \%$ when the Te concentration in the aqueous solution exceeded $0.5 \mathrm{~g} / \mathrm{L}$ (Figure 5). This result suggests that, to maintain a good efficient extraction, the concentration of TBP should be increased when that of Te gets higher than $0.5 \mathrm{~g} / \mathrm{L}$.

3.8. Effect of Organic to Aqueous Volume Ratio. Different volume ratios of organic to aqueous phase were tested and the results shown in Table 5 indicate that the extraction increased with an increasing $\mathrm{O} / \mathrm{A}$ phase ratio, reaching a maximum value at $2: 1$. However, considering the sharp increase extraction when the $\mathrm{O} / \mathrm{A}$ phase ratio was changed from $1: 2$ to $1: 1$, a preferred $\mathrm{O} / \mathrm{A}$ phase ratio of $1: 1$ was adopted to avoid a large consumption of organic solution.

3.9. Effect of Repeated Extraction. The aqueous phase solution of $0.5 \mathrm{~g} / \mathrm{L} \mathrm{Te}(\mathrm{IV})$ in $4.5 \mathrm{~mol} / \mathrm{L} \mathrm{HCl}$ was extracted three times 
TABLE 7: Effect of the stripping agent on Te(IV) extraction.

\begin{tabular}{lc}
\hline Agent & Extraction of Te/\% \\
\hline $\mathrm{H}_{2} \mathrm{O}$ & 73.70 \\
$20 \%(\mathrm{w} / \mathrm{v}) \mathrm{NH}_{4} \mathrm{Cl}$ & 99.56 \\
$1 \mathrm{~mol} / \mathrm{L} \mathrm{NaOH}$ & 98.93 \\
$0.5 \mathrm{~mol} / \mathrm{L} \mathrm{HCl}$ & 93.10 \\
\hline
\end{tabular}

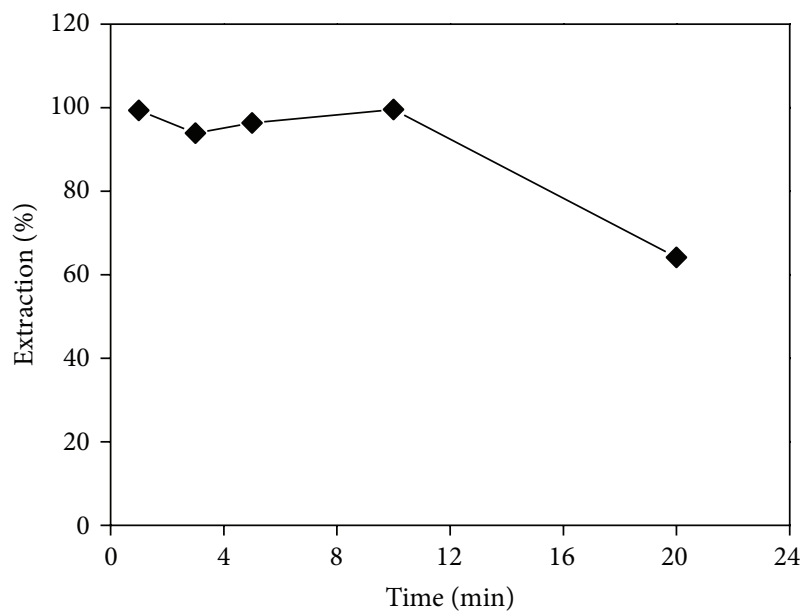

FIgURE 6: Effect of stripping time on Te(IV) extraction.

by the $30 \%(\mathrm{v} / \mathrm{v})$ TBP solution in kerosene. Each equilibration time was $3 \mathrm{~min}$. Results show that the extraction increased with the increasing number of extractions (Table 6). It reached up to a maximum of $98.97 \%$ after 3 extractions and this should be the preferred number of extractions for such a system.

3.10. Effect of Stripping Agents. Solutions of Te extracted into TBP in kerosene were submitted to different types of stripping agents. The mixture of the organic and stripping solutions were strongly shaken and then left to obtain a clear phase separation. The results (Table 7) show that stripping with water only was incomplete and inefficient in comparison with using a $20 \%(\mathrm{w} / \mathrm{v})$ ammonium chloride solution, $1 \mathrm{~mol} / \mathrm{L}$ sodium hydroxide, and $0.5 \mathrm{~mol} / \mathrm{L}$ hydrochloric acid. Considering the high efficiency and the low corrosion effect of the ammonium chloride solution, it was chosen as the best stripping agent.

3.11. Effect of Stripping Time. The effect of time on the stripping of Te was tested by shaking for different lengths of time using the $20 \%(\mathrm{w} / \mathrm{v})$ ammonium chloride solution. As revealed in Figure 6, Te in the organic phase was almost stripped completely within $1 \mathrm{~min}$ but the extraction efficiency showed some fluctuations with extended time. A $10 \mathrm{~min}$ stripping time proved to be the most efficient with $99.39 \%$, but it went sharply down to $64.19 \%$ when the time was prolonged to $20 \mathrm{~min}$, since a very high stripping efficiency and a clear phase separation could be obtained within only $1 \mathrm{~min}$, which time was chosen for stripping Te.
TABLE 8: Effect of diverse ions on Te(IV) extraction.

\begin{tabular}{lcc}
\hline Ions & $\begin{array}{c}\text { Amount } \\
\text { taken } /\left(\mathrm{mg} \cdot \mathrm{L}^{-1}\right)\end{array}$ & $\begin{array}{c}\text { Amount } \\
\text { determined } /\left(\mathrm{mg} \cdot \mathrm{L}^{-1}\right)\end{array}$ \\
\hline $\mathrm{K}^{+}$ & 9.9 & 9.3 \\
$\mathrm{Na}^{+}$ & 6.5 & 6.5 \\
$\mathrm{Ca}^{2+}$ & 9.3 & 9.0 \\
$\mathrm{Mg}^{2+}$ & 5.8 & 5.7 \\
$\mathrm{Fe}^{3+}$ & 2.9 & 3.2 \\
$\mathrm{Cu}^{2+}$ & 11.2 & 11.8 \\
$\mathrm{Mn}^{2+}$ & 11.0 & 11.7 \\
\hline
\end{tabular}

3.12. Effect of Diverse Ions. Finally, the effect of diverse common ions on the recovery of Te was investigated by adding different amounts of selected ionic species $\left(\mathrm{K}^{+}\right.$, $\mathrm{Na}^{+}, \mathrm{Ca}^{2+}, \mathrm{Mg}^{2+}, \mathrm{Fe}^{3+}, \mathrm{Cu}^{2+}$, and $\mathrm{Mn}^{2+}$ ). The amount of each ionic species added to the extraction system before extraction (taken amount) and after extraction (determined amount) was examined. The data in Table 8 indicate that these common ions do not interfere with the extraction of $\mathrm{Te}$ in $4.5 \mathrm{~mol} / \mathrm{L} \mathrm{HCl}$ with $30 \%(\mathrm{v} / \mathrm{v}) \mathrm{TBP}$ in kerosene at $1: 1 \mathrm{O} / \mathrm{A}$ ratio.

\section{Conclusion}

Different parameters were investigated for the extraction of tellurium species from an acid medium. In consideration of cost, time, use of solvent, and overall efficiency, it was determined that the extraction of an aqueous solution of $0.5 \mathrm{~g} / \mathrm{L}$ $\mathrm{Te}(\mathrm{IV})$ was the best in $4.5 \mathrm{~mol} / \mathrm{L} \mathrm{HCl}$ with an organic solution containing $30 \%(\mathrm{v} / \mathrm{v}) \mathrm{TBP}$ in kerosene at an organic/aqueous $(\mathrm{O} / \mathrm{A})$ volume ratio of 1 , with a contact time of $3 \mathrm{~min}$ and 3 repeated extractions. The Te extraction in such system can reach a $99 \%$ recovery. The stripping agent and stripping time were also looked into for Te(IV) from the organic solution and a $20 \%(\mathrm{w} / \mathrm{v})$ ammonium chloride solution was chosen with a stripping time of $1 \mathrm{~min}$ and the stripping rate was up to 99\%. Further, based on the experiment data, the extraction reaction was found to be neutral complex mechanism, and the extracted species in the organic phase is $\mathrm{TeCl}_{4} \cdot 3 \mathrm{TBP}$. The extraction efficiency decreased with the increasing temperature. The extraction reaction is an exothermic process. The thermodynamic functions of enthalpy $(\Delta H)$, entropy $(\Delta S)$, and free energy $(\Delta G)$ of the Te extraction with TBP have been evaluated at the chosen conditions.

\section{Conflict of Interests}

The authors declare that there is no conflict of interests regarding the publication of this paper.

\section{Acknowledgments}

Financial support from the National Natural Science Foundation of China (Grants 21276194 and 20776019) is greatly 
acknowledged. A special recognition goes to the late Associate Professor Mengxia Liao from the Chengdu University of Technology for her valuable assistance. Authors also hope to thank the editor and the anonymous reviewers for their active comments on the paper.

\section{References}

[1] B. M. Sargar and M. A. Anuse, "Liquid-liquid extraction study of tellurium(IV) with N-n-octylaniline in halide medium and its separation from real samples," Talanta, vol. 55, no. 3, pp. 469478, 2001.

[2] D. K. Mandal, B. Bhattacharya, and R. D. Das, "Recovery of tellurium from chloride media using tri-iso-octylamine," Separation and Purification Technology, vol. 40, no. 2, pp. 177-182, 2004.

[3] G. S. Desai and V. M. Shinde, "Extraction and separation studies of tellurium(IV) with tris-(2-ethyl hexyl) phosphate," Talanta, vol. 39, no. 4, pp. 405-408, 1992.

[4] M. R. Chowdhury and S. K. Sanyal, "Separation by solvent extraction of tellurium(IV) and selenium(IV) with tri-n butyl phosphate: some mechanistic aspects," Hydrometallurgy, vol. 32, no. 2, pp. 189-200, 1993.

[5] M. Bandyopadhyay, S. Datta, and S. K. Sanya, "Correlation of mass transfer coefficients for tellurium(IV) extraction with instantaneous reaction in a modified Lewis cell," Hydrometallurgy, vol. 42, no. 1, pp. 115-123, 1996.

[6] Y.-C. Zhao, A. I. Zouboulis, and K. A. Matis, "Flotation of molybdate oxyanions from dilute solutions Part II. Selective separation from phosphates, arsenates and silicates," Hydrometallurgy, vol. 43, no. 1-3, pp. 155-167, 1996.

[7] A. Ramesh and M. S. Subramanian, "Extractive separation of selenium and tellurium using 2,3,5-triphenyltetrazolium chloride," Bulletin of the Chemical Society of Japan, vol. 71, no. 5, pp. 1025-1030, 1998.

[8] Y. V. Ghalsasi, S. S. Khopkar, and V. M. Shinde, "Extractive separation of tellurium(IV) with triphenylarsine oxide and tributylphosphine oxide as extractants," Indian Journal of Chemistry A, vol. 38, no. 6, pp. 621-623, 1999.

[9] S. P. Jagatap, S. S. Kolekar, S. H. Han, and M. A. Anuse, "Liquid-liquid extraction of selenium(IV) and tellurium(IV) by N-n-octylcyclohexamine followed by their spectrophotometric determination," Reseach Journal of Chemical Science, vol. 3, no. 1, pp. 72-81, 2013.

[10] T. L. Deng, M. X. Liao, Y. F. Guo, and N. Zhang, "Tellurium speciation analysis in aqueous environment by HG-AFS," in Proceedings of the 4th Asian-Pacific International Conference on Pollutant Analysis and Control, pp. 60-61, Beijing, China, October 2007.

[11] M. R. Chowdhury and S. K. Sanyal, "Diluent effect on extraction of tellurium (IV) and selenium (IV) by tri-n butyl phosphate," Hydrometallurgy, vol. 34, no. 3, pp. 319-330, 1994. 

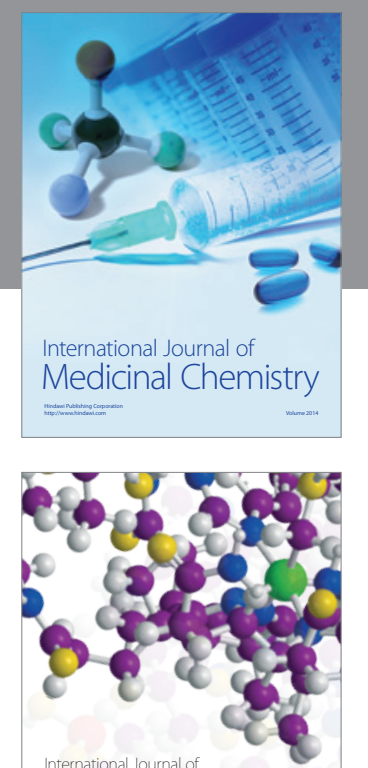

\section{Carbohydrate} Chemistry

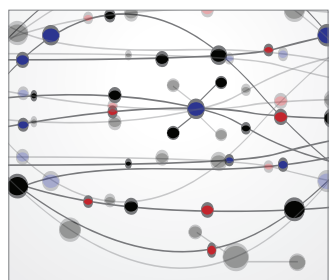

The Scientific World Journal
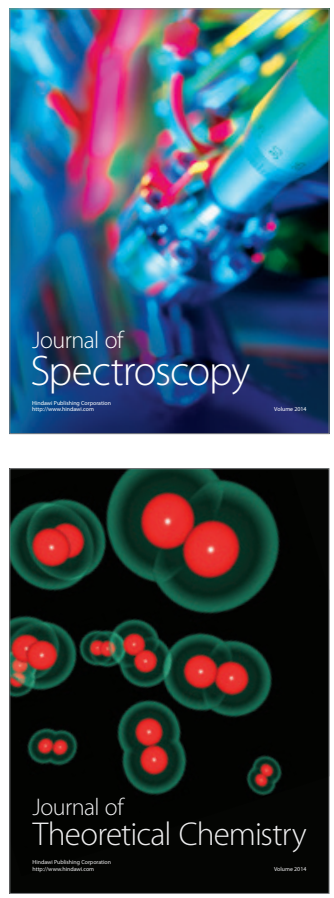
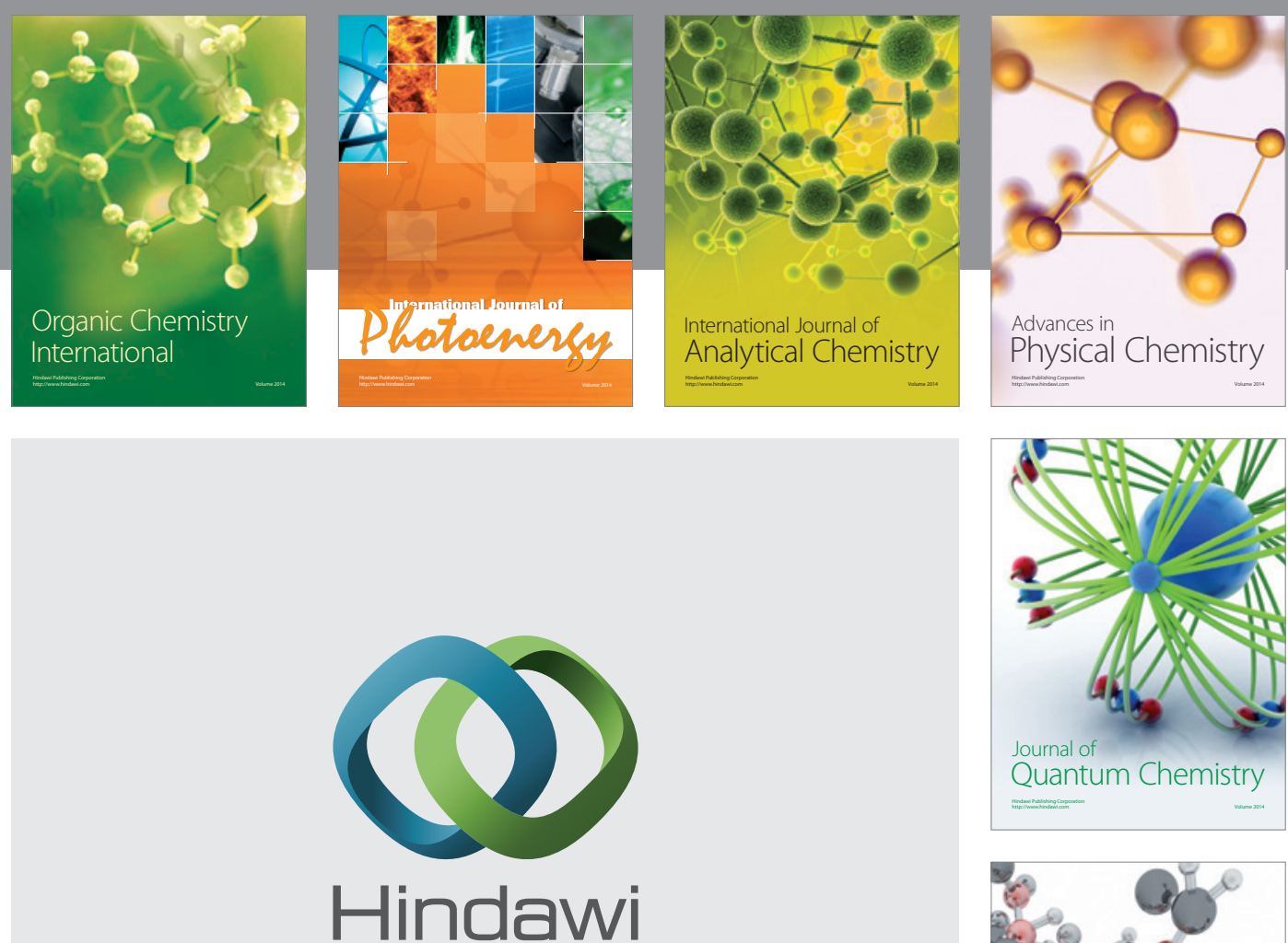

Submit your manuscripts at

http://www.hindawi.com

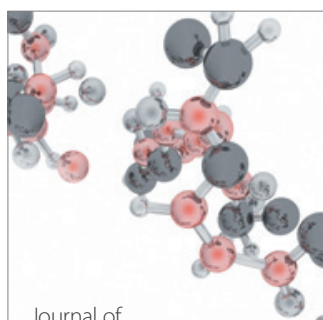

Analytical Methods

in Chemistry

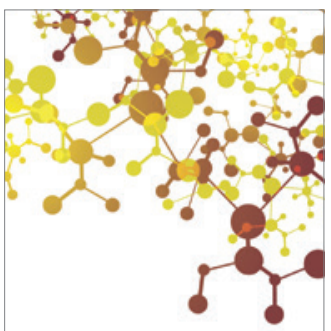

Journal of

Applied Chemistry

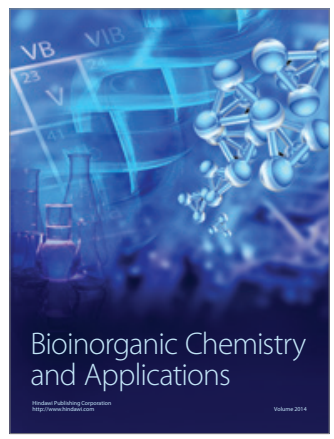

Inorganic Chemistry
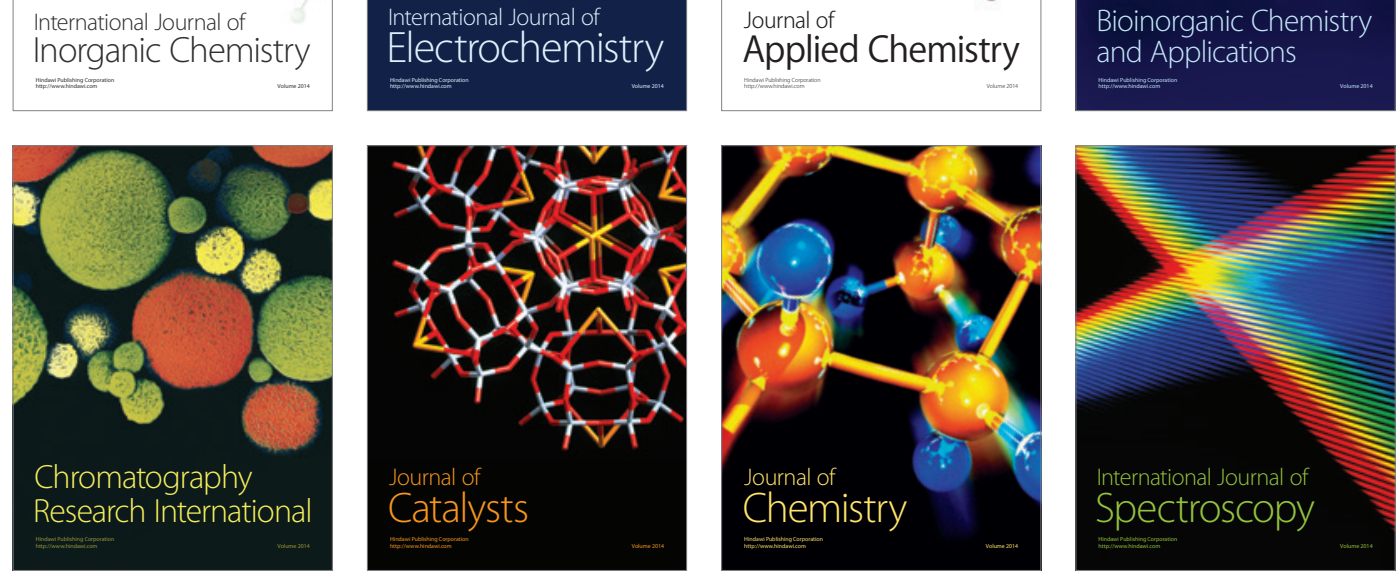